\title{
Issues in Obtaining Promotion
}

\author{
William E. Seifert Jr. • Leonard J. Cleary • Henry W. Strobel
}

Published online: 23 October 2014

(C) International Association of Medical Science Educators 2014

\section{Introduction}

The choice of an academic career is highly attractive for its creative opportunities and its collegial working environment. Basic scientists and clinicians share a devotion to discovery of new knowledge, a desire to teach, and a desire to apply that knowledge by advancing the field or by tending to the welfare of others. Those who embark on this career path may do so with varying degrees of self-confidence that their hopes will be fulfilled. Yet, all faculty members of allopathic and osteopathic medical schools as well as universities and colleges anticipate that their careers will be advanced by promotion.

In earlier work, we advanced the idea that the relationship between faculty and the institution constitutes a covenantal interaction rather than a mere contractual one [1].

W. E. Seifert Jr. $(\varangle) \cdot$ L. J. Cleary $\cdot$ H. W. Strobel

The University of Texas Medical School at Houston, The University of Texas Health Science Center at Houston, 6431 Fannin Street, Houston 77030, TX, USA

e-mail: william.e.seifert@uth.tmc.edu

W. E. Seifert Jr. • L. J. Cleary $\cdot$ H. W. Strobel

The University of Texas Graduate School of Biomedical Sciences at Houston, The University of Texas Health Science Center at Houston, 6767 Bertner Ave., Houston 77030, TX, USA

\section{J. Cleary}

Department of Neurobiology and Anatomy, Medical School, The University of Texas Health Science Center at Houston, 6431 Fannin Street, Houston, TX 77030, USA

\section{W. E. Seifert Jr.}

McGovern Center for Humanities and Ethics, The University of Texas Health Science Center at Houston, 6431 Fannin Street, Houston 77030, TX, USA

\section{H. W. Strobel}

Department of Biochemistry and Molecular Biology, Medical School, The University of Texas Health Science Center at Houston, 6431 Fannin Street, Houston 77030, TX, USA
We examined the state of tenure [2] and analyzed the effects of a relative value unit (RVU)-based system on the function of the university as a whole [3]. More recently, we described transitions in academic life [4]. Here we focus on what is for many the most important transition-promotion.

\section{Aspects of the Current State of Promotion}

The Association of American Medical Colleges (AAMC) maintains a unique Faculty Roster database on employment, training, and demographics of individual US medical school faculty that allows the analysis of faculty promotion trends. A 2010 AAMC Analysis in Brief article [5] reported a study of promotions from assistant to associate and from associate to full professor between 1967 and 1997. The 10-year averaged rates for promotion from assistant professor to associate professor dropped from 43.5 to $32.8 \%$. Moreover, the average time to promotion in this group rose from 5.2 to 6.2 years. A similar though less dramatic decrease in rate (41.7 to $38.6 \%$ ) and an increase in time to promotion (5.7 to 6.1 years) were determined for promotions from associate to full professor.

A more specific analysis was undertaken to examine changes in the number of full-time M.D.-holding clinical faculty on the tenure track. This analysis revealed a decline from $57 \%$ in 1985 to $42 \%$ in 2004 [6] with a commensurate rise in the proportion of those on a non-tenure track from 34 to $50 \%$. This may be correlated with data showing that only 45 of 111 institutions $(41 \%)$ reported that tenure for clinical faculty was associated with specific compensation guarantees, and 45 out of 119 institutions ( $38 \%$ ) reported similar guarantees for basic science faculty, contrary to the historic links between salary and tenure of past decades [7].

One consequence of increasing the number of non-tenuretrack faculty, especially those with short-term contracts, is a decreased emphasis on committee functions, mentoring, and 
advising students, all critical activities without which the institution cannot adequately function [8]. Without sufficient recognition, these functions now fall to a decreasing number of faculty members, increasing the burden on those willing to participate.

\section{On What Basis Should Promotion Be Awarded?}

Promotion in academia should be awarded on the basis of merit, specifically on the basis of scholarly excellence [9]. We argue that merit is expressed in three areas: excellence of contributions, a consistent record of contributions, and continuing creativity.

Excellence of Contributions Traditionally, academic institutions are based on excellence. There are many varieties of excellence, including the formulation of new theories, teaching, research, translation of new discoveries into new technologies or treatment strategies, and academic leadership [10]. Excellence in each of these areas is judged by criteria specific to the area.

Consistent Record of Contributions The second area important for promotion is a consistent record of contributions over the course of one's academic career. For example, scholarly activity may focus on one area or it may encompass a series of research topics pursued in concert or episodically. Note that the length of time in service is generally not a factor in the promotion process. An important exception, however, is the decision to grant tenure, which must be made within a circumscribed amount of time, e.g., 7-10 years.

Creativity The third area of merit in faculty life is that of creativity. One's skills and training must be used to keep ahead of the field by discerning new fronts within one's area that are ripe for new approaches to address central questions. For those with an emphasis on education, new ways of collaborating across fields may offer students improved didactic experiences. For example, an integrated curriculum that combines disciplines to approach clinical problems from a scientific, collaborative base rather than an algorithmic base may be more efficient for the training of medical students than the traditional approach. The creativity required to formulate and implement an integrated curriculum is a basis of merit that may support promotion to higher academic rank.

\section{Suggested Practices for the Promotion Process}

In reviewing the current state of academic promotion and the bases on which promotion should be awarded, we believe that the promotion process in most academic institutions could be improved. We therefore proffer some practices for the institution and the faculty member we believe will improve the process of promotion.
What Can the Institution Do to Assist the Faculty Member in the Promotion Process?

Prepare and Promulgate Clear Definitions, Procedures, and Expectations The first thing an academic institution can do to aid a faculty member through the promotion process is to prepare and promulgate clear definitions, procedures, and expectations for the process either online or in the faculty handbook or both. Definition includes providing clarity about what promotion tracks and pathways exist. Most academic institutions start with two tracks, a tenure track and a nontenure track. Further subdivisions of the tenure track may include a scientist scholar, a clinician scholar, and an educator scholar pathway. The non-tenure track may be subdivided into research, clinician, and educator pathways as well. These titles may vary, and there may be additional steps and grades. The challenge is to articulate the expectations for each title. Most institutions adhere to the philosophy that the title, track, and pathway should fit what the faculty member actually does, and therefore, the promotion criteria will be appropriate for the specific roles. Procedures will vary from institution to institution [11-14], but criteria by which promotion will be decided in most institutions include the following:

Scholarly Contributions. This area includes publications of original work resulting from laboratory research, clinical research, and/or educational innovations, applications, and research. Dissemination of scholarly work occurs through presentations at local, regional, national, and international venues as well as publication of papers, reviews, invited chapters, and books.

Teaching Contributions. These contributions can be made in formal lectures, seminars, problem-based learning sessions, group learning sessions, as well as clinical rounds and bedside or benchside teaching. It is important that teaching contributions be documented and evaluated by departmental peers as well as trainees.

Service Contributions. Clinical service in the form of clinic time or surgeries and procedures is a major faculty activity. Service to the institution at the division, department, school, and institution or national levels in the form of committee work, review panels, specialty and subspecialty boards, or examination groups as well as community service are also important contributions.

Peer Esteem. The perception of peers outside one's institution is essential for assessment of one's contributions to the field. Generally, evidence for peer esteem is provided in letters solicited by the institution from leaders in the field nominated by the individual and/or the institution. These letters attest to the impact of the candidate's contribution to the field. 
Annual Reviews of the Faculty Member's Accomplishments and Goals for the Coming Year Most institutions have in place an annual faculty review process. Most commonly, the process begins with the faculty member's summary of the year's accomplishments/activities in scholarly activity, teaching, clinical service, and committee services. The faculty member is usually asked to assess the degree to which these activities met last year's goals and to offer goals for the upcoming year. Typically, the faculty member's curriculum vitae (CV) and teaching evaluations are included and sent to a divisional/departmental peer committee for assessment. That peer committee assessment is attached and sent to the departmental chair for comments. The last phase is a face-to-face discussion of all the preceding components of the review and the chair's comments with the faculty member. Out of this discussion should come an agreement on goals for the next year and an approach as to how these goals may be achieved. At the appropriate time, these assessments should include a timetable for progress toward promotion.

Mentoring Mentoring in most institutions is coaching a new (or established) faculty member toward the next level of faculty life. There may be one mentor (though this is rare) or a series of mentors each of whom is chosen or assigned for a particular phase of faculty life. The role of the mentor is to help the faculty member on the journey to maximum expression of potential. Thus, the mentor should strike a balance between advising and doing. A good mentor must enable, but not direct, the mentee [15-17].

Other promising practices in place in some institutions are the following:

New Faculty Orientation. This may be held at the departmental or school-wide level. The goal is twofold: to show the institutional services/resources available to the new faculty member and to provide an opportunity to situate the first year's activities in the context of the requirements for promotion within the span of the next 4-5 years. A school-wide orientation also offers an opportunity for a new faculty member to meet contemporaries from other departments as well as deans and administrators of the school.

First-Year Faculty Review. This review has good possibilities of setting in place a process of reviewing the year annually in terms of progress toward promotion. The annual faculty review occurs in the department, whereas this progress toward promotion can occur with the faculty mentor, division leader, or faculty affairs personnel. Rather than focusing on assessment, this interview can focus strictly on progress toward promotion and what steps can be put in place to provide/produce the benchmarks needed. For instance, a mentor may suggest that a mentee give poster presentations at meetings in order to network and discuss their work with members of the field as a way to develop a list of potential outside letter writers for promotion.

Promotion Seminars. These seminars are offered to faculty who have been in residence 3 to 4 years. They deal with the nuts and bolts of the institutional promotion process and are helpful to faculty in drawing together the information needed in the $\mathrm{CV}$, assessing and describing the contributions made to scholarship, service and teaching in a coherent overview. Faculty affairs personnel read CVs, make suggestions for additions and changes, and help faculty identify potential letter writers by describing the kinds of information the promotion committee expects from reference letters.

Mock Promotion Committee Meetings. Members of the promotion committee at the department or school level stage the promotion committee discussion of three synthesized faculty members proposed for promotion/tenure. The three dossiers are distributed to the audience so they can read and evaluate them, and then the committee and committee chair conduct a mock meeting exactly like a real meeting. Afterwards, there is a discussion of what was present in the dossiers, how it was evaluated by the committee, and how the decisions were determined. This session has led to increased awareness of the promotion process.

Together these items comprise an array of strategies an institution might use to help faculty members through the promotion process. Many are in use in most institutions. Those missing may be initiated easily.

What Can the Faculty Member Do to Facilitate Promotion?

Before Accepting a Faculty Member Position The path to promotion starts when one accepts the first appointment at an institution. Therefore, as part of the decision-making process, one should obtain the written criteria for advancement at the departmental and school levels. The basic elements should be the same at all institutions (i.e., achievement criteria in each of the appropriate levels), although specific expectations may vary from department to department (e.g., number of research grants, teaching roles, number of teaching hours, etc.). In addition, it would behoove the prospective faculty member to discuss with various members of the department the informal common knowledge issues that may play a role in successfully being promoted.

Comply with Written Criteria and Verbal Advice Promotion is a logical process rooted in peer evaluation. Following school procedures to provide all the information needed for evaluation leads to successful outcomes in the vast majority of cases. 
In our medical school, we posit that each faculty member should be promotable on the basis of the four $D$ s:

- Doing. This includes teaching trainees of all ranks, doing research (whether experimental or patient-based), and doing service (whether clinical or committee)

- Discovery. This entails being a skilled observer with a prepared mind. Research findings, the development of pedagogical methods or modules, and the analysis of patient outcomes and other results fall into this category

- Dissemination. This category includes making results and discoveries known. In addition to publications, dissemination is accomplished by attending conferences to present findings, accepting invitations to present results at other schools and institutions, and developing a network of colleagues and collaborators within and outside the institution.

- Documentation. This includes publication of the results of scholarly activity in journals, as chapters in an edited volume or in a book. Educational materials published online or in other appropriate repositories of learning objects as videos or computer programs may also be an acceptable evidence of scholarly activity. Document each of these accomplishments in the $\mathrm{CV}$.

Using the four Ds will help the faculty member prepare his/ her CV for review for promotion. The annual departmental $\mathrm{CV}$ and progress review process is a valuable tool for faculty members seeking promotion, for it is through these reviews that feedback for areas of weakness can be obtained and the deficits can be repaired. Mentors, colleagues, and students may also provide informal or formal feedback.

Demonstrate and Record Excellence The faculty member must understand that the steps of academic promotion focus on different (though similar) aspects of academic life, and therefore, these aspects must be recorded $[13,18]$.

Assistant Professor to Associate Professor. This step focuses on the individual contributions and abilities of the faculty member. The candidate is expected to develop recognition in the various areas of academic life including a record of publication or dissemination of a body of work, peer recognition for that work obtained through letters of evaluation, and local, regional, and national stature obtained through grants, invitations to deliver lectures, study section service, and/or other signs of having an established presence at the institution, such as active participation on institutional committees.

Associate Professor to Full Professor. Promotion to full professor requires excellence in the same areas but focuses especially on evidence of national and international reputation expressed in peer letters and by invitations to lecture at national/international meetings, editorial positions, committee service at national/international levels, and the like.

For each of these promotion steps, the most effective way to obtain a national or international reputation is to present one's work and actively participate at national or international meetings.

Promotion in Academia Is Based on Peer Evaluation Peer review is the academic standard for assessment. Thus, promotion decisions, indeed even the annual evaluation, are ultimately made by faculty peers whether by vote of a designated committee in the department or by the whole department. The advantage is that faculty peers know the research, teaching, or clinical work the candidate does and the committees on which the candidate sits, because by and large, they have done the same things. It therefore follows that peer esteem within the school/university and outside the university is critical. Letters obtained from colleagues inside and outside of the university are the chief means of documenting the peer evaluation and esteem of a candidate for promotion. Selection of letter writers is a critical choice for the candidate and the department to make, especially for outside letter writers. The most important document for the letter writer's use is the CV. Therefore, in addition to asking a potential letter writer for his/her willingness to write a letter, the preparation of an up-to-date, accurate, and easily interpretable CV is of central importance. A summary statement of one's work and its impact for the letter writer's use is also often helpful in that it draws attention to items documented in the $\mathrm{CV}$.

Seek Institutional Assistance Successful outcomes are of benefit both to the individual and the institution. Most institutions have an Office of Faculty Affairs (whether that is the name or not) that can answer institution-specific promotion questions.

A critical feature of institutional assistance is faculty development. At our institution, assistance in promotion planning, CV preparation, and career track planning is housed in the Office of Faculty Affairs, while faculty skill development in teaching is housed in the Office of Educational Programs. In addition to managing the curriculum for undergraduate medical students and the training of residents and fellows, the Office of Educational Programs offers various programs on lecture preparation, lecture delivery, small group leadership, bedside teaching, etc. Faculty may benefit from this continuing education at the time they begin their roles as educators. Most, if not all, institutions have offices that carry out these functions. All good sources of information and assistance should be used by the faculty member. 


\section{Conclusions}

For many academic scientists, the path to promotion and tenure is clear: generate research grants and publish papers. Nevertheless, the operation of medical schools and academic hospitals requires a broad range of expertise. The pathway to promotion for individuals whose activities primarily benefit the institution may not be as clear. Because faculty success is in the best interest of all parties, the requirements for and pathways to promotion should be clearly stated in promotion guidelines and clearly articulated by department chairs and faculty affairs offices. Activities in other areas, e.g., scholarship, dissemination of discoveries, committee service, etc., are taken into consideration, but exceptional achievement in specific areas should nonetheless be rewarded. In this way, the institution retains and rewards faculty gifted in specific areas, and the faculty member moves forward in academia.

Does using multiple categories of contribution for promotion introduce unfairness due to nonuniformity of criteria? We do not think so, because excellence is the unifying category by which all criteria are assessed. By applying this standard uniformly and evenly, the contributions of all faculty members can be assessed and rewarded without bias toward particular areas of expertise.

\section{References}

1. Seifert Jr WE, Strobel HW. Faculty and academic institution: a covenantal relationship. Med Sci Educ. 2011;21-1:37-41.

2. Seifert Jr WE, Strobel HW. A proposal for tenure. Med Sci Educ. 2011;21-4:375-81.
3. Seifert Jr WE, Strobel HW. Values, RVUs and teaching. J Int'l Assn Med Sci Educ. 2010;20-2:62-6.

4. Strobel HW, Seifert Jr WE. Transitions in medical education and medical educators. Med Sci Educ. 2014;24-3:343-347. doi:10.1007/s40670014-0030-5.

5. AAMC. Analysis in brief May 2010.

6. AAMC. Analysis in brief March 2007.

7. AAMC. Analysis in brief April 2010.

8. Katz S. The usual suspects. The Chronicle of Higher Education, June 25,2010

9. Boyer EL. Scholarship reconsidered: priorities of the professoriate. San Francisco: Jossey-Bass; 1990.

10. Gardner JW. Excellence: can we be equal and excellent too? New York: Harper and Row; 1961. p. 127-34.

11. Harvard Medical School Office for Faculty Affairs. Promotion policies. http://www.fa.hms.harvard.edu/administrator-resources/ appointment-and-promotion/promotion-policies/. Accessed 17 Oct 2014.

12. Duke University School of Medicine. Faculty Appointments, Promotion and Tenure Office. http://medschool.duke.edu/faculty/ faculty-apt-office. Accessed 17 Oct 2014.

13. The University of Texas Medical School at Houston. Faculty appointments, promotions \& tenure guidelines. https://med.uth.edu/ faculty-affairs/files/2013/06/2009-Revised-FAPTC-Guidelines.doc. Accessed 17 Oct 2014.

14. Michigan State University. Health programs faculty appointment system handbook. http://www.hr.msu.edu/documents/facadadhandbooks/ healthproghandbook/index.htm. Accessed 17 Oct 2014.

15. Nick JM, Delahoyde TM, Del Prato D, Mitchell C, Ortiz J, Ottley C, et al. Best practices in academic mentoring: a model for excellence. Nurs Res Pract. 2012;2012:937906. doi:10.1155/2012/937906.

16. Fox S, Corrice A. Mentoring in academic medicine: the current state of practice and evidence-based alternatives. https://www.aamc.org/ download/257862/data/mentoring_in_acadmed_current_state.pdf. Accessed 17 Oct 2014.

17. Detsky AS, Baerlocher MO. Academic mentoring - how to give it and how to get it. JAMA. 2007;297(19):2134-6.

18. University of North Carolina at Chapel Hill School of Medicine. Guidelines for appointment, reappointment and promotion of faculty. http://www.med.unc.edu/www/about/administration/files/SOMAPT. pdf. Accessed 17 Oct 2014. 